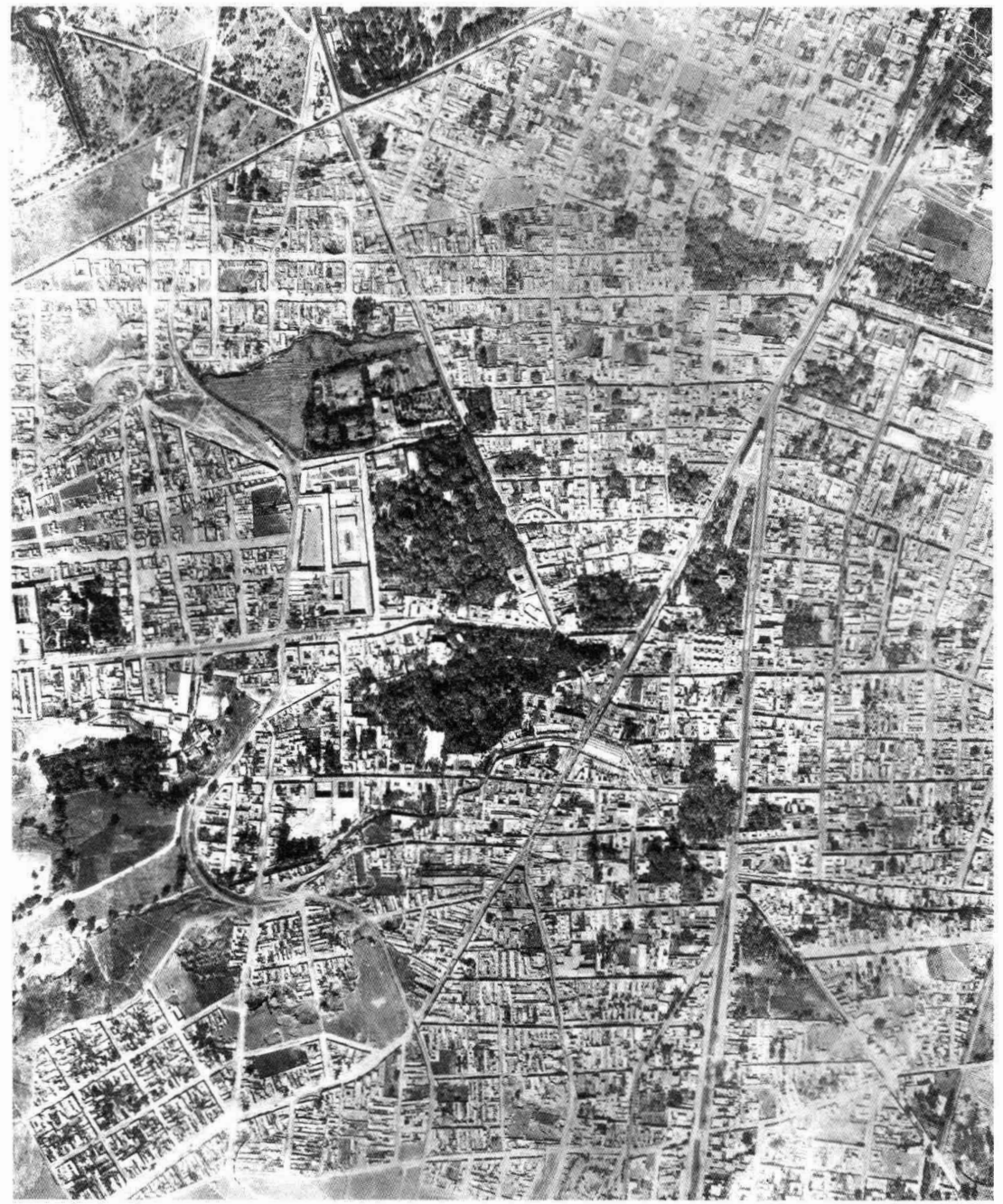




\section{Ernest Sánchez Santiró}

Doctor en geografía e historia. Profesor investigador en el Área de Historia Económica del Instituto de Investigaciones Dr. José María Luis Mora. Pertenece al Sistema Nacional de Investigadores. Entre sus libros destacan: Azúcar y poder. Estructura socioeconómica de las alcaldias mayores de Cuernavaca y Cuautla de Amilpas, 1730 1821, Universidad Autónoma del Estado de Morelos/Praxis, México, 2001, 331 pp., y El padrón del Arzobispado de México de 1777, Archivo General de la Nación, México, 2003, 170 pp. En la actualidad, sus líneas de trabajo fundamentales son la producción y la circulación de la agroindustria azucarera mexiquense en la primera mitad del siglo xIx; la fiscalidad mexicana en el siglo XIX, y la minería del centro de Nueva España en el siglo XVIII.

\section{Resumen}

El propósito de este trabajo es realizar un análisis demográfico de la capital del virreinato de Nueva España en el momento de máximo esplendor del reformismo carolino, a partir del estudio del padrón del arzobispado de México de 1777. El análisis de la información registrada en dicho padrón sobre la ciudad de México se plantea en dos niveles. Por una parte, se propone la comparación de la urbe con el conjunto de la archidiócesis, lo cual permite visualizar las particularidades demográficas que presentaba la capital novohispana en relación con el resto del virreinato. Por otra parte, se establece un desglose y contraste en el ámbito parroquial, base territorial sobre la que se levantó el padrón, con el propósito de sacar a la luz los grandes contrastes internos de la ciudad, los cuales constituían una de las notas más características de su fisonomía urbana. Como parte del análisis, nos proponemos también entrar en la problemática de la evolución demográfica de la ciudad a lo largo del siglo XVIII.

Palabras clave:

Población, ciudad de México, siglo xvir, parroquias.

\section{Abstract}

This paper contains a demographic analysis of New Spain's capital during the peak of Charles III's reformism, by examining the 1777 census of the archbishopric of Mexico. The analysis of the information recorded in this census of Mexico City is conducted on two levels. On the one hand, it compares the city with the archdiocese as a whole, enabling the reader to visualize the demographic particularities of the capital of New Spain in relation to the rest of the viceroyalty. At the same time, it undertakes a breakdown and comparison of the data at the parish level, the territorial basis on which the census was carried out, to highlight the enormous internal contrasts of the city, which constituted one of the most characteristic features of its urban physiognomy. As part of the analysis, we also propose exploring the problem of the city's demographic evolution during the $18^{\text {rl }}$ century.

\section{Key words:}

Population, Mexico City, $18^{\text {th }}$ century, parish churches.

Fecha de recepción: enero de 2004

Fecha de aceptación: abril de 2004 


\title{
La población de la ciudad de México en $1777^{*}$
}

\author{
Ernest Sánchez Santiró
}

\section{INTRODUCCIÓN}

$\mathbf{E}$ 1 propósito de este trabajo es realizar un análisis demográfico de la capital del virreinato de Nueva España en el-momento de máximo esplendor del reformismo carolino. Un reformismo que pretendió efectuar trabajos demográficos como parte de la política impulsada por los Borbones que buscaba reforzar los instrumentos de poder de la monarquía católica. Censos, padrones de población destinados a otorgar información lo más amplia, fiable y precisa posible sobre los vastos y diversos territorios coloniales que, junto a otros elementos, permitiesen mantener y reforzar el control de la corona sobre los territorios ultramarinos. ${ }^{1}$

* Quiero agradecer al geógrafo Oscar J. Jurado el apoyo cartográfico así como el trabajo de determinación del área de las parroquias de la ciudad de México en 1777. También agradecer el apoyo bibliográfico de Pilar Gonzalvo Aizpuru.

${ }^{1}$ En toda la literatura arbitrista y mercantilista de la época moderna, el "buen gobierno" de una república por parte de su soberano incluía la obtención de información ajustada a las realidades sobre las que se pretendía actuar. Parte fundamental de dicho acervo lo constituía la información de padrones y censos que, en última instancia, podían acabar teniendo una función fiscal o militar. Véanse Grice-Hutchinson, Pensamiento, 1982, pp.162-233; Perdices y Reeder, Mercantilismo, 1998, pp. 59-122.
En este contexto, Carlos III determinó en los años setenta del siglo Xvir la realización de padrones generales para el conjunto de la América hispana y Filipinas. ${ }^{2}$ Entre las diversas iniciativas emprendidas destaca la real orden de San Lorenzo del Escorial de 10 de noviembre de 1776, en la que se estipulaba que los virreyes "hagan exactos padrones con la debida distinción de clases, estados y castas de todas las personas de ambos sexos, sin excluir a los párvulos".

En el caso concreto del virreinato de Nueva España, la mayor parte de esta obra demográfica fue realizada por las autoridades eclesiásticas, concretamente por los obispos de Puebla, Oaxaca, Durango y el arzobispo de México, Alonso Núñez de Haro y Peralta, a lo largo de 1777 y parte de $1778 .^{3}$

El análisis de la información registrada en dicho padrón sobre la ciudad de México en 1777 , se plantea en dos niveles.

${ }^{2}$ La política de Carlos III de levantar padrones, y no meramente relaciones geográficas o matrículas de tributarios, en el conjunto de los territorios americanos se muestra evidente si observamos la cronología de los principales censos de población de la época: 1.775 , la Capitanía General de Cuba; 1777, Nueva España, Perú y Chile; 1778, Guatemala, Nueva Granada y Río de la Plata. Sánchez-Albornoz, Población, 1994.

${ }^{3}$ Para ver la problemática de la realización de estos padrones, véase Sánchez, Padrón, 2003, pp. 15-31. 
Por una parte, proponemos la comparación de la urbe con el conjunto de la archidiócesis, lo cual permite visualizar las particularidades demográficas que presentaba la capital novohispana en relación con el resto del virreinato. Por otra parte, establecemos un desglose y contraste en el ámbito parroquial, base territorial sobre la que se levantó el padrón, con el propósito de sacar a la luz los grandes contrastes internos de la ciudad, los cuales constitúan una de las notas más características de su fisonomía urbana. Como parte del análisis, nos proponemos también entrar en la problemática de la evolución demográfica de la ciudad a lo largo del siglo XVIII.

En relación con la fuente básica de este trabajo, ${ }^{4}$ cabe decir que el padrón del arzobispado de México en 1777 presenta seis elementos relevantes en cuanto a la ciudad de México: los cuadros resumen los padrones de las catorce parroquias de la capital erigidas en 1772 (véase mapa 1); ${ }^{5}$ un cuadro con la población de los conventos de regulares, otro de los conventos de religiosas, dos más sobre los colegios (masculinos) y de educandas de México, un cuadro sobre los cuerpos veteranos y provinciales (militares) del arzobispado $\mathrm{y}$, finalmente, un cuadro resumen por castas, estados y clases de la población total de la ciudad de México. A partir de estos elementos, pretendemos establecer deter-

${ }^{4}$ Archivo General de Indias (en adelante AGI), Indiferente, leg. 1525 (trasladado a la sección de Mapas y Planos, Varios, microfilm 38, rollo 20).

${ }^{5}$ Éstas eran: El Sagrario, San Miguel, Salto del Agua, San Pablo, Santa Cruz Acatlán, Santo Tomás la Palma, Santa Cruz y Soledad, San Sebastián, Santa Caterina Mártir, San Ana, Santa María la Redonda, Santa Veracruz, San José y la parroquia rural de San Antonio de las Huertas, al occidente de la ciudad. Moreno, "Territorios", 1981. minados rubros: población total, composición étnica, densidad de población, procesos migratorios, estructura familiar, etc., que permitan responder a las cuestiones planteadas en el trabajo mediante un análisis que combine una visión sincrónica, un corte temporal de la ciudad de México en 1777 , con una perspectiva diacrónica, en especial al comparar la información del mencionado padrón con los datos y estudios realizados a partir del padrón de Fuenclara de 1743 y el de Revillagigedo de 1790 .

\section{LA EVOLUCIÓN DE LA POBLACIÓN TOTAL DE LA CIUDAD DE MÉXICO}

Uno de los aspectos más controvertidos, dada la carencia de fuentes confiables, es el de la evolución de los montos totales de la población de la capital virreinal a lo largo del siglo XVIII y la primera mitad del siglo XIX. La gráfica 1 sintetiza los principales datos y estimaciones con los que contamos en la actualidad. ${ }^{6}$

${ }^{6}$ Un problema básico de estos datos es que no se pude determinar de forma clara en la totalidad de ellos el espacio sobre el cual se levantaron los padrones o se realizaron las estimaciones de población. ¿Englobaban sólo la zona urbanizada y semirrural próxima? ¿Incluían la totalidad del territorio político? ¿Coincidía plenamente el territorio político de la ciudad de México en el periodo colonial y en el periodo republicano? Esto, añadido a los problemas propios de una época preestadística, hace que la gráfica aquí presentada sólo se pueda emplear como orden de magnitud que permite plantear la problemática sobre ciertas cuestiones, como es la evolución demográfica de la ciudad de México en el tránsito de la colonia a la independencia. En todo caso se ha intentado presentar los datos más relevantes que poseemos sobre dicha evolución. 


\section{SECUENCIA}

Mapa 1. Densidades de población de las parroquias de la ciudad de México, 1777

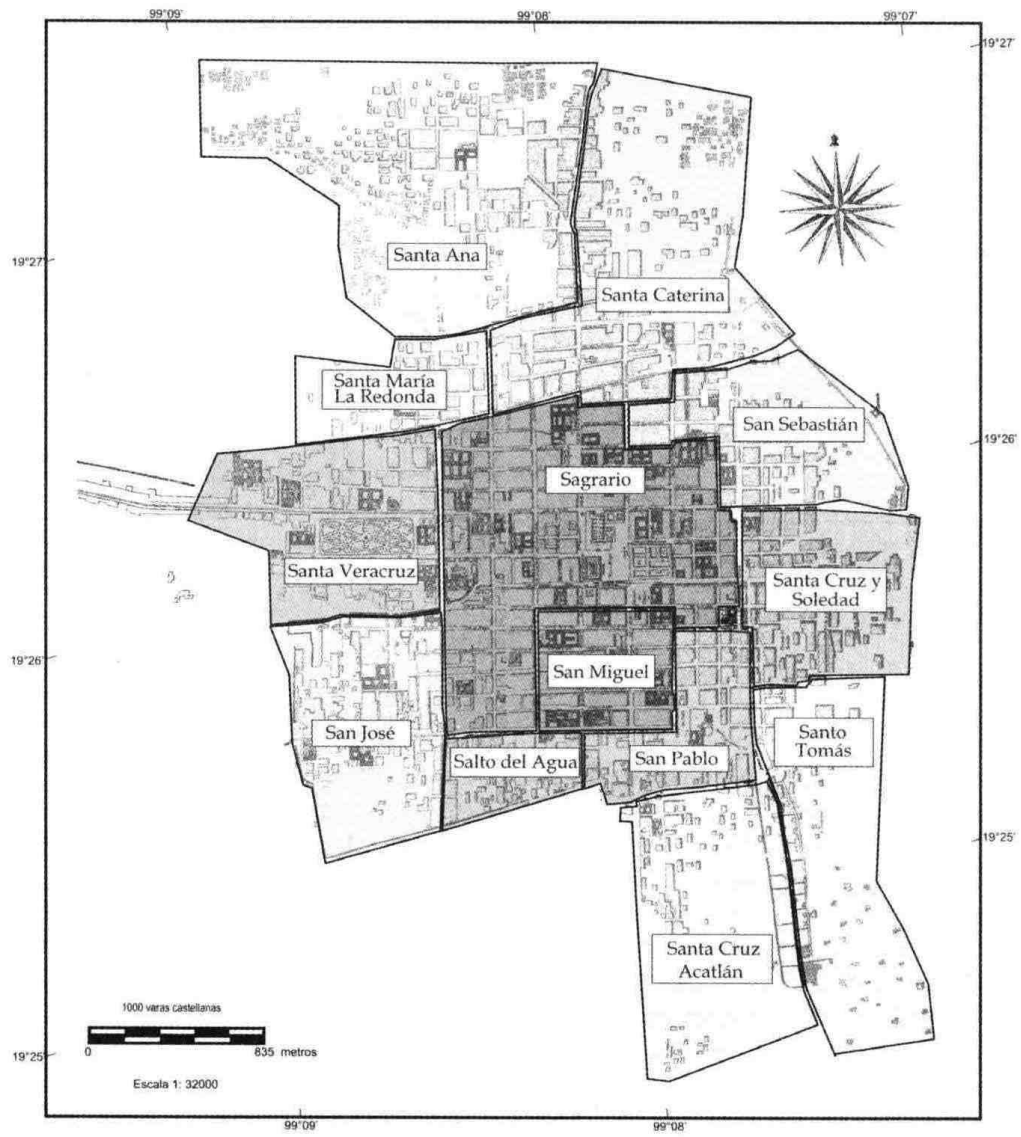

\section{Densidad de población}

Menos de 10000 habitantes por $\mathrm{km}^{2}$

De 10000 a 20000 habitantes por $\mathrm{km}^{2}$

Más de 20000 habitantes por $\mathrm{km}^{2}$

Edición cartográfica: Oscar Josué Jurado Gutiérrez.

Fuente: Lombardo, Atlas, 1996, vol. I, pp. 57 y 31.

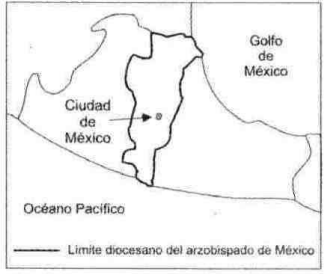

Fuente: Taylor, Ministros, 1996. 
Gráfica 1. Evolución demográfica de la ciudad de México (1689-1852)

Totales

(miles)

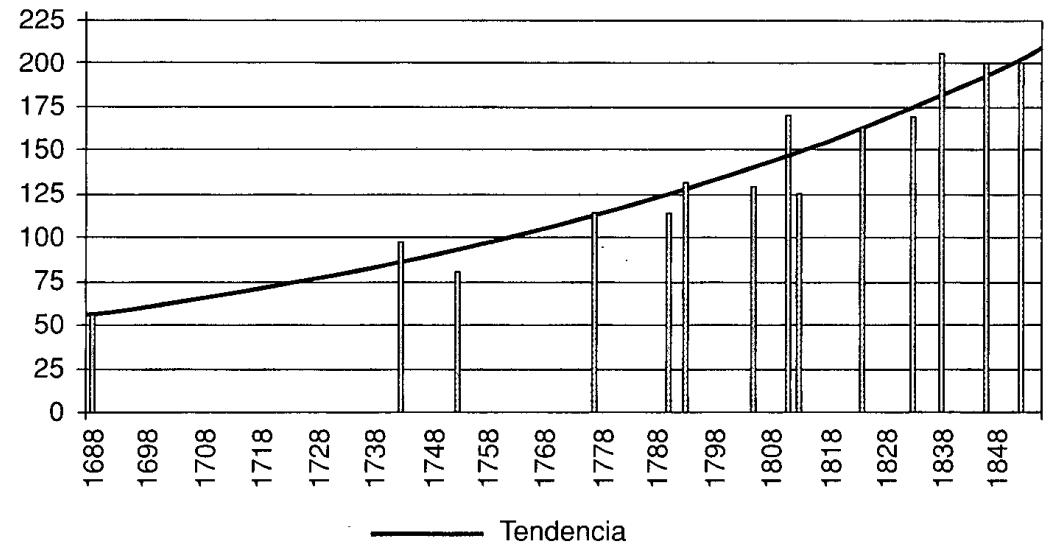

Fuente: Apéndice, cuadro 1.

En primer lugar una breve explicación sobre los datos aquí expuestos. La población de 1689 , un total de 57000 habitantes, procede de una estimación que Ignacio Rubio Mañé realizó a partir de su estudio sobre la población peninsular/ europea en la ciudad de México en dicho año. ${ }^{7}$ Los 98000 habitantes de la ciudad en 1746 surgen de la reinterpretación de los datos que aporta José Antonio Villaseñor y Sánchez en su obra Theatro americano. El problema fundamental es que $\mathrm{Vi}$ llaseñor indica que la ciudad tenía 50000 familias de españoles, 40000 de castas y 8000 indios. Tal y como indicaba Ignacio Rubio Mañé, la cita del autor aplicada tanto a españoles como a la población de

\footnotetext{
${ }^{7}$ Rubio, "Gente", 1966, p. 13.
}

castas, más que referirse a familias, parecería que representaba el número de individuos. ${ }^{8}$ La estimación de población en 1753 de 80000 habitantes surge del análisis del padrón levantado a partir de la división por cuarteles de la ciudad aplica-

${ }^{8}$ Ibid., p. 11. Hay que indicar que estos datos también presentan un problema en cuanto a la división de dicha población en calidades étnicas. Si bien el porcentaje de españoles $(50 \%)$ se corresponde con el registrado para la ciudad en 1777 (49.8\%) y $1790(50.3 \%)$, el porcentaje de castas $(40 \%)$ y de indios $(8 \%)$ de 1746 es claramente erróneo, al sobreestimar a los primeros y subestimar a los segundos. En 1777, la población de castas representaba $23 \%$ de la ciudad y en 1790 era $25 \%$, mientras que la población india en las mismas fechas era 27 y $25 \%$ respectivamente. Véase Sánchez, Padrón, 2003, p. 54; Castro, México, 1988, p. 222. 
da a la ciudad en $1750 .{ }^{9}$ Los principales problemas de este padrón son la ausencia de la población de uno de los cuarteles mayores (la cual su supone en la estimación total) y que la población de los cuarteles que circundaban a la traza presenta subregistros. Los datos de 1777 y de 1790 (así como su proyección a partir de este último en 1804 por parte del Consulado de Mercaderes de la ciudad de México y en 1805 por parte de Alejandro de Humboldt), producto de padrones elaborados con unos criterios de recolección de la información bastante completos y muy homogéneos, son los más fiables para todo el siglo XVII y principios del siglo XIX. La cifra de 1811, de más de 168000 habitantes, muestra el momento excepcional que vivió la ciudad al acoger a la población de provincias que huía de la insurgencia, mientras que los datos de 1813 presentan también un fuerte subregistro. ${ }^{10} \mathrm{El}$ resto de datos procede de diversos recuentos de población y estimaciones realizados por varios intelectuales/políticos de la época (1824, Joel R. Poinsett; 1846, Thomas J. Farnham; 1852, M. Orozco y Berra), por el calendario de Galván (caso del año de 1833) o por organismos creados por la república con el propósito de realizar dichas tareas (1838, Junta Menor del Instituto Nacional de Geografía y Estadística). ${ }^{11}$

Prescindiendo ahora del dato, muy poco fiable, de 1689 , y ciñéndonos a la evolución demográfica de la ciudad entre 1746 y 1852 , podemos apreciar varios elementos. La ciudad, a lo largo del perio-

\footnotetext{
9 Báez, "Planos", 1967, p. 488.

${ }^{10}$ Orozco, "Ciudad", 1854.

${ }^{1.1}$ Davis, "Tendencias", 1972, p. 501.
}

do, mostró una tendencia claramente ascendente con una tasa de crecimiento anual de $0.67 \%$, aunque desigualmente repartida. Así, entre mediados del siglo XVIII y principios del XIX (1746-1805), la población creció a un ritmo mucho menor, concretamente $0.48 \%$ anual, que durante la primera mitad del siglo XIX (1805 y 1852), al llegar a $0.92 \%$ anual, lo cual nos habla de un periodo tardocolonial con graves dificultades para la capital virreinal.

En este sentido, el análisis exhaustivo de la mortandad catastrófica de la parroquia capitalina de Santa Caterina Mártir realizado por Juan Javier Pescador es paradigmática del proceso vivido por la ciudad. ${ }^{12} \mathrm{El}$ autor establece claramente dos etapas, $1670-1770$ y $1770-1820$, en las cuales la parroquia, y por ende, la ciudad, sufrió crisis demográficas de distinta intensidad. Así, tras las fuertes crisis de 1692-1693 y 1696-1697, la población capitalina tuvo casi 40 años de estabilidad hasta la grave epidemia de matlazabuatl de 1737, que diezmó de forma considerable a la población. Algunos autores, caso del presbítero Cayetano Cabrera, con un claro sesgo exagerado llegaron a considerar que más de 40000 personas habrían muerto en ese año. Tras este evento, las crisis por viruela (1747), matlazahuatl (1761), otra vez viruela (1762) y sarampión (1768) golpearon con menor intensidad a la población de la parroquia. A pesar de la intensidad de algunas de estas crisis demográficas, caso de 1737, tal y como indica J. J. Pescador, el espaciamiento entre severas crisis (entre 25 y 40 años) hizo que la evolución poblacional del curato -cabría añadir de la ciudad-

${ }^{12}$ Pescador, Bantizados, 1992, pp. 94-106. 
no sufriese lesiones irreversibles. ${ }^{13}$ Por el contrario, el periodo de 1770-1820, con fuertes crisis de mortandad en 1779 , $1784,1786,1797,1804$ y 1813 , con una intensidad de mortandad catastrófica superior, en promedio, a la etapa anterior y, lo más relevante, con periodos de recuperación más breves, nos presenta una población capitalina sometida a un "devastador deterioro de sus condiciones de vida que la puso a merced de epidemias cada vez más frecuentes y destructoras". En ese sentido, los 112462 habitantes registrados en la ciudad en el padrón de 1777 representarían el final de un ciclo de evolución positivo iniciado tras la epidemia de 1737. Las inmediatamente sucesivas epidemias acaecidas entre 1779 y 1786 debieron provocar un fuerte estancamiento, lo cual refuerza el análisis de Gonzalo Aguirre Beltrán quien, al hablar de la población total de la colonia en 1777 en relación con el padrón de 1790, indicaba: "es indudable que por 1777 el total de la colonia era mayor que durante la gestión del virrey Revillagigedo". ${ }^{14}$

A partir de este panorama consideramos que la estimación de 170000 habitantes en la ciudad de México en 1790 realizada por Manuel Miño merece diversos comentarios. ${ }^{15}$ En primer lugar, prescinde del factor diacrónico en el que las crisis

${ }^{13}$ Aunque el autor, muy prudentemente, limite el resultado de su análisis a la demografía de una única parroquia, difícilmente eventos demográficos como la epidemia de 1737 o las de $1761-1762$ podían quedar limitados al pequeño territorio del curato, máxime cuando nos referimos a un espacio urbano bastante circunscrito con continuos movimientos de población en su interior y altas densidades de población en el medio rural.

${ }^{14}$ Aguirre, Población, 1989, p. 231.

${ }^{15}$ Miño, "Población", 2002, p. 23. demográficas de 1779,1784 y 1786 no habrían afectado a la ciudad, es más, la población habría aumentado en cerca de 58000 habitantes entre 1777 y 1790 , al pasar de 112462 habitantes a 170000 respectivamente. En segundo lugar, porque en caso de ser acertada tal estimación, significaría que la ciudad de México en 1790 habría alcanzado el mismo nivel de población que el obtenido en la década de los años treinta del siglo xIX, lo cual implicaría que la ciudad habría vivido un periodo de unos 40 años de estancamiento demográfico. Evidentemente, la otra opción es considerar que los padrones, recuentos y estimaciones de 1777 , 1790,1805 y 1833 , todos ellos, presentaban graves subregistros, lo cual aboga por la postura del citado autor.

\section{DENSIDAD DE POBLACIÓN}

El padrón de la ciudad de México de 1777 permite introducirnos en el problema de la distribución de la población en el territorio. Una primera aproximación nos muestra la fuerte concentración de la población en el territorio de la partoquia de El Sagrario, con $31 \%$, seguido por Santa Caterina con $13 \%$, la Santa Veracruz con 9\% y San Miguel con $8 \%$. Parroquias localizadas en el centro de la urbe, especialmente El Sagrario y San Miguel, herederas de las advocaciones y templos de las antiguas cuatro parroquias de españoles existentes en la ciudad entre 1690 y 1772. Sin embargo, si combinamos los datos del padrón de 1777 y el mapa del mismo año de la ciudad de México realizado por Ignacio Castera, con el mapa que realizó José Antonio de Alzate en 1769 como parte de los trabajos prepara- 
torios para efectuar la división parroquial de la ciudad de México en $1772,{ }^{16}$ podemos precisar el tema de la densidad demográfica y su distribución en la capital virreinal (véase cuadro 1$){ }^{17}$

Primeramente hay que aclarar el territorio considerado aquí (véase mapa 1). De cara a establecer la densidad demográfica de la ciudad se ha tenido en cuenta la zona urbana central de la ciudad de México así como el territorio semiurbanizado circundante, aparecido en el mapa parroquial realizado por Alzate en 1769 , sin incluir en él las diversas poblaciones dispersas más alejadas, ni la parroquia rural de San Antonio de las Huertas al occidente, en el camino al pueblo de Tacuba. ${ }^{18}$

Tal y como podemos apreciar, sobre una superficie de $10.62 \mathrm{~km}^{2}$ se asentaba una población de 103152 habitantes (sin incluir ahora religiosos, colegiales ni militares), lo cual arrojaba una densidad

${ }^{16}$ Moreno, Territorios, 1981, pp. 169-170.

${ }^{17}$ Lombardo, Atlas, 1996, vol. I, pp. 56-57, 331. Se ha tomado como mapa base para las densidades de población el realizado por el arquitecto Ignacio Castera por dos razones. En primer lugar porque dicho mapa representa, a diferencia del de Alzare, la siruación de la ciudad de México en un año más próximo a la realización del padrón, 1776. En segundo lugar, por la calidad y fiabilidad superior en cuanto a la factura del trabajo cartográfico de Castera respecto del de Alzate. Este último, únicamente pretendía con su obra indicar las áreas que iban a ocupar las distintas parroquias, apuntando algunos núcleos y zonas relevantes de la ciudad en 1769 , mientras que el trabajo de Castera se propuso asentar las calles, plazas y edificaciones de la urbe, indicando en la mayoría de los casos los nombres de las vías y de los principales inmuebles, ya laicos, ya religiosos.

${ }^{18}$ Una exposición de espacio rural que abarcaban las parcialidades de indios de la ciudad de México la tenemos en Lira, Comunidades, 1995. de población de 9713 habitantes por kilómetro cuadrado. ${ }^{19}$ Sin embargo, los contrastes aparecen. Dos parroquias, El Sagrario y San Miguel, que ocupaban casi $100 \%$ de la antigua traza española del siglo XVI, tenían altísimas densidades al superar los 20000 habitantes por $\mathrm{km}^{2}$. En el siguiente rango (entre 10000 y 20000 habitantes) se encontraba un conjunto de parroquias circundantes a la traza - San Pablo, Salto del Agua, Santa Veracruz y Santa Cruz y Soledad- mientras que las restantes siete parroquias, Santa Caterina, San Sebastián, San José, Santa María la Redonda, Santa Ana, Santo Tomás y Santa Cruz Acatlán, poseían densidades inferiores a los 10000 habitantes por $\mathrm{km}^{2}$. Parroquias éstas con un hábitat disperso, mayoritariamente indígena en los tres últimos casos citados, en el cual se entreveraban espacios urbanizados con solares deshabitados empleados para usos agrícolas y ganaderos. ${ }^{20}$

\section{COMPOSICIÓN Y DISTRIBUCIÓN ÉTNICA DE LA CIUDAD DE MÉXICO}

Por lo que hace a este aspecto, primero es necesario definir algunos conceptos. En la época, el término "castas" era empleado como sinónimo de "calidades". De hecho, el estado general de la población del arzobispado de México de 1777 substituyó

19 Arturo Sotomayor apunta una superficie para la ciudad de México de aproximadamente $11 \mathrm{~km}^{2}$ en 1800 . Véase Sotomayor, Expansión, 1975, p. 49.

20) Para un trabajo que muestra esa presencia del mundo rural en la urbe capitalina que atiende preferentemente a los usos del agua y lo pastos de las parcialidades de indios de México, véase Dávalos, "Ispacios", 2002. 
Cuadro 1. Densidades de población por parroquias en la ciudad de México, 1777

$\begin{array}{lccc}\text { Parroquias } & \text { Superficie }\left(\mathrm{km}^{2}\right) & \text { Población } & \text { Densidad de población } \\ \text { San Miguel } & 0.36 & 8295 & 23042 \\ \text { Sagrario } & 1.47 & 32668 & 22223 \\ \text { San Pablo } & 0.39 & 6646 & 17041 \\ \text { Salto del Agua } & 0.23 & 3250 & 14130 \\ \text { Santa Veracruz } & 0.81 & 9164 & 1131.4 \\ \text { Santa Cruz y Soledad } & 0.63 & 6741 & 10700 \\ \text { Santa Caterina } & 1.35 & 13396 & 9923 \\ \text { San Sebastián } & 0.64 & 5440 & 8500 \\ \text { San José } & 0.76 & 5340 & 7026 \\ \text { Santa María la Redonda } & 0.36 & 2030 & 5639 \\ \text { Santa Ana } & 1.76 & 5540 & 3148 \\ \text { Santo Tomás } & 0.9 & 2706 & 3007 \\ \text { Santa Cruz Acatlán } & 0.95 & 1936 & 2038 \\ \text { Total ciudad de México } & 10.62 & 103152 & 9713 \\ & & & \\ \text { a No incluye clérigos ni militares. } & & \end{array}$

el primer término por el segundo, frente a lo ordenado por Carlos III en su real orden de 1776.

El Diccionario de autoridades de la Real Academia daba la siguiente definición en el siglo XVIII del término calidad: "la propiedad del cuerpo natural y naturalmente (salvo el poder de la omnipotencia divina) inseparable de la substancia [...] Calidad. Se llama la nobleza y lustre de la sangre." ${ }^{21}$ Lo consustancial a los cuerpos naturales en cuanto a las calidades era la generación y linaje del cual se procedía, la "sangre" que se portaba, la cual determinaba, según sus composiciones, la separación por etnias entendidas éstas como un estatus racial definido por "el color le-

${ }^{21}$ Diccionario, 1990, t. 1, p. 67. Véase Sánchez, Padrón, 2003, pp. 40-42. gal". ${ }^{22}$ Es preciso indicar que la adscripción de las calidades a cada uno de estos grupos sociorraciales por parte de los individuos, constituía un verdadero ejercicio de autodefinición, ${ }^{23}$ de forma que, a la altura del último tercio del siglo XVIII, no se podía apelar a realidades "objetivas" que, sin lugar a dudas, pudiesen determinar a qué casta pertenecía cada uno de los sujetos.

Los más de de 1.00000 habitantes de la ciudad de México en 1777 presentaban una composición étnica bastante disímil en relación con su distribución en el resto del arzobispado, en especial en las zonas rurales $y$, por ende, del virreinato, tal y como podemos apreciar en el cuadro 2 .

${ }^{22}$ McCaa, "Calidad", 1984, p. 478.

${ }^{23}$ Tomamos el concepto a partir del trabajo de Rabell, Oaxaca, 2001, p. 4. 
Cuadro 2. Distribución por calidades de la población de la ciudad de México en 1777

$\begin{array}{lcc}\text { Calidades } & \text { Población total } & \text { Porcentaje } \\ \text { Españoles } & 50465 & 44.9 \\ \text { Indios } & 30227 & 26.9 \\ \text { Mestizos } & 13009 & 11.6 \\ \text { Mulatos } & 7467 & 6.6 \\ \text { Castizos } & 4088 & 3.6 \\ \text { Otros }^{\mathrm{a}} & 1737 & 1.5 \\ \text { Clérigos }^{\mathrm{b}} & 5469 & 4.9 \\ \text { Totales } & 112462 & 100.0\end{array}$

" Otros: moriscos, mestindios, negros, lobos, albinos y coyotes.

${ }^{b}$ No es una calidad sino un estado.

Fuente: Apéndice, cuadro 2.

La ciudad de México aparece con una composición demográfica totalmente desequilibrada en la medida que la población española y la formada por militares y eclesiásticos (también de origen español en su mayoría) alcanzaba $50 \%$ del total, mientras que la población indígena apenas ascendía a $27 \%$, a la vez que la población de castas representaba $23 \%$ de la capital virreinal. Por el contrario, la distribución étnica del arzobispado de México, el territorio novohispano más poblado, presentaba un panorama muy distinto al poseer una población mayoritariamente indígena (67\%), seguida de la población "de castas" (19\%), mientras que la población asentada en el padrón como "española" sólo alcanzaba $14 \% .{ }^{24}$ Cabe apuntar que si comparamos esta distribución étnica capitalina de 1777 con la registrada en el padrón de la ciudad de México de $1790,{ }^{25}$ se aprecian dos elementos. Por una parte, el mantenimiento

\footnotetext{
${ }^{24}$ Sánchez, Padrón, 2003, p. 50 y Apéndice, cuadro 3.

${ }^{25}$ Castro, México, 1988, p. 222.
}

del porcentaje de población española, alrededor de $50 \%$, mientras que la población de castas adquirió un leve impulso al pasar de 23 a $25 \%$, a la vez que la población india perdía presencia en la ciudad, al descender de 27 a $25 \%$ del total de la población empadronada en dichos años. Un movimiento que, en tan breve espacio de tiempo, cabe atribuir a una leve mortandad diferencial superior en la población indígena respecto del resto de etnias en las epidemias de 1779, 1784 y 1786 , así como a un movimiento de inmigración de población mayoritariamente femenina de criollas, mestizas, mulatas y negras, tal y como veremos más adelante.

Las funciones políticas, administrativas y religiosas, así como la concentración del poder económico de la capital virreinal quedan bien patentes ante esa gran concentración de población "española" en su recinto, tal y como podemos ver en el cuadro 3.

El contraste entre la archidiócesis y la ciudad de México, una vez más, es patente. Una administración religiosa en el arzobispado que se limitaba a los titulares 
Cuadro 3. Presencia de clérigos y militares en la archidiócesis y la ciudad de México, 1777

$\begin{array}{lrrrr}\text { Estado } & \text { Arzobispado } & \text { Porcentaje } & \text { Ciudad de México } & \text { Porcentaje } \\ \text { Civiles } & 1183676 & 99.2 & 105039 & 93.4 \\ \text { Clérigos }^{\mathbf{a}} & 8077 & 0.6 & 5469 & 4.9 \\ \text { Militares } & 2469 & 0.2 & 1956 & 1.7 \\ \text { Totales } & 1191753 & 100.0 & 112464 & 1.00 .0\end{array}$

"Incluye curas, clérigos, regulares, monjas, colegiales y colegialas.

Fuente: Sánchez, Padrón, 2003.

de los distintos curatos, por lo general con un solo clérigo en cada uno de ellos, más 766 religiosos (dominicos, observantes, agustinos, mercedarios, franciscanos, betlemitas, etc.) y 131 monjas clarisas y capuchinas, junto a 123 colegiales y 305 colegialas, ubicados todos ellos de forma mayoritaria en Querétaro, Toluca, Tepozotlán, Pachuca y Tacubaya. Con relación a la presencia militar fuera de la ciudad, ésta quedaba circunscrita al regimiento de caballería provincial de la ciudad de Querétaro con apenas 513 efectivos. Ambos grupos, incluyendo los datos de la ciudad de México, sólo representaban $0.8 \%$ del total de la población del arzobispado. ${ }^{26}$

Frente a una presencia eclesiástica y militar mínima en un espacio arzobispal que alcanzaba los 116090 kilómetros cuadrados, ${ }^{27}$ observamos cómo en el recinto urbano capitalino ambos grupos contabilizaban $6.6 \%$ del total de la población. Un segmento poblacional que, a excepción de los 728 componentes del batallón de pardos de la ciudad de México, poseían la calidad étnica de españo-

\footnotetext{
${ }^{26}$ Sánchez, Padrón, 2003, pp. 142-152.

${ }^{27}$ Gerhard, México, 1962, p. 18.
}

les. No sólo eso, pertenecían a una elite capitalina que gozaba de los privilegios inherentes al fuero eclesiástico y militar. Su presencia en la capital, junto a un poderoso y exclusivo sector de mercaderes y hacendados, es uno de los factores que explicará gran parte de su gran potencial económico como mercado consumidor y articulador del centro del virreinato de Nueva España.

Sin embargo, la distribución étnica en el interior de la propia capital virreinal no era homogénea. El padrón de 1777 deja traslucir dos fenómenos. Por una parte, los restos del proyecto fundacional del siglo XVI destinado a mantener separadas las repúblicas de indios (San Juan Tenochtitlan y Santiago Tlatelolco) de la república de españoles conformada por población española y de castas, genéricamente denominadas gente de razón. Por otra parte, se detecta el quebrantamiento de dicho proyecto al haber ocupado la gente de razón gran parte de los espacios destinados, tal y como veremos, a la población indígena.

La composición tripartita de la capital virreinal tras la conquista, ${ }^{28}$ esto es, la conformada por las dos ciudades herma-

${ }^{28}$ Moreno, “Territorios”, 1981, pp. 158-159. 
nas prehispánicas, Tenochtitlan y Tlatelolco, y la ciudad española incrustada entre ambas, México, acabó articulándose de forma similar a su administración política al crearse dos parcialidades/barrios de indios (San Juan Tenochtitlan y Santiago Tlatelolco), alrededor de la ciudad hispana. ${ }^{29}$ Esta división política acabó teniendo también su reflejo parroquial. ${ }^{30}$

La separación, justificada en aras tanto de la seguridad de los conquistadores como con base en el objetivo de evangelización de la población indígena de la ciudad, ${ }^{31}$ adquirió forma urbana mediante la delimitación de la traza (inicialmente una superficie de trece leguas cuadradas) en la parte central de la antigua capital tenochca. Ejecutada mediante calles organizadas ortogonalmente por Alonso García Bravo en 1521, esta área fue reservada para la población española, toda vez que se obligó al traslado de la población indígena al espacio denominado por los españoles "barrios" o parcialidades de indios. Concretamente, en la parcialidad de San Juan Tenochtitlan quedaron cuatro barrios (campan) de origen prehispánico: Cuepopan, al noroeste; Atzacoalco, al noreste; Teopan, al sureste, y Moyotla, al suroeste, mientras que al norte quedó la

${ }^{29}$ Lira, Comunidades, 1995, passim.

${ }^{30}$ Moreno, "Territorios", 1981, pp. 160-161.

31 Evangelización entendida en un sentido más amplio que la mera introducción de nuevos principios religiosos y que pasaba por la enseñanza de un nuevo idioma, el castellano, el aprendizaje de nuevos artes y oficios, así como la implantación de instituciones sociales, políticas, jurídicas y económicas ajenas al mundo prehispánico, con un objetivo claro: la incorporación del "indio" a la cultura cristiana europea. Véase O'Gorman, "Reflexiones", 1938, pp. 795-797; Gibson, Aztecas, 1984, p. 63; Lira, Comunidades, 1995, p. 18. parcialidad de Tlatelolco. ${ }^{32}$ Estamos pues ante un proyecto de zonificación étnica de la ciudad de México, que destinaba el centro capitalino a la población española y la periferia urbana a la indígena.

La historia que va de 1521 a mediados del siglo XVIII sobre la distribución étnica de la población es el relato del quebrantamiento continuo de dicho ordenamiento jurídico. A medida que la población no india, la gente de razón, crecía en la urbe, se fue asentando más allá de los límites de la traza, ocupando parte de los barrios indios, mientras que diversos contingentes de población indígena se introducían en ella. Aunque la corona intentó impedir la ruptura de este orden político merced a diversas reales cédulas que confirmaban la separación entre indios y no indios, ${ }^{33}$ las autoridades civiles y eclesiásticas de la ciudad no pudieron detener un proceso que respondía a los cambios económicos y sociales que vivió la urbe capitalina desde el siglo XVI. Cambios que hacían referencia a una realidad económica y social que demandaba mano de obra, en este caso indígena, para talleres, comercios y servicios de la población de la traza capitalina, la cual generó una demanda de alojamiento que fue satisfe-

${ }^{32}$ Lira, Comunidades, 1995, p. 26.

${ }^{33}$ En el caso de los españoles se prohibía que viviesen en las localidades de indios merced a la real cédula de 23 de agosto de 1538 (asentada en la Recopilación de leyes de Indias -ley 19 , título $1^{\circ}$, libro $6^{\circ}-$ ), mientras en el caso de los mulatos, mestizos y negros fue a través de la real cédula de 2 de mayo de 1563 (Recopilación de leyes de indias -ley 21, título $3^{\circ}$, libro $6^{\circ}$ ). Un ordenamiento que el caso de la ciudad de México se reiteraría en 1692 y 1753. O'Gorman, "Reflexiones", 1938, pp. 800, 804 y 807; Báez, "Planos", 1966, p. 466; Torre, "Demarcación", 2000, pp. 93-94. 


\section{SECUENCIA}

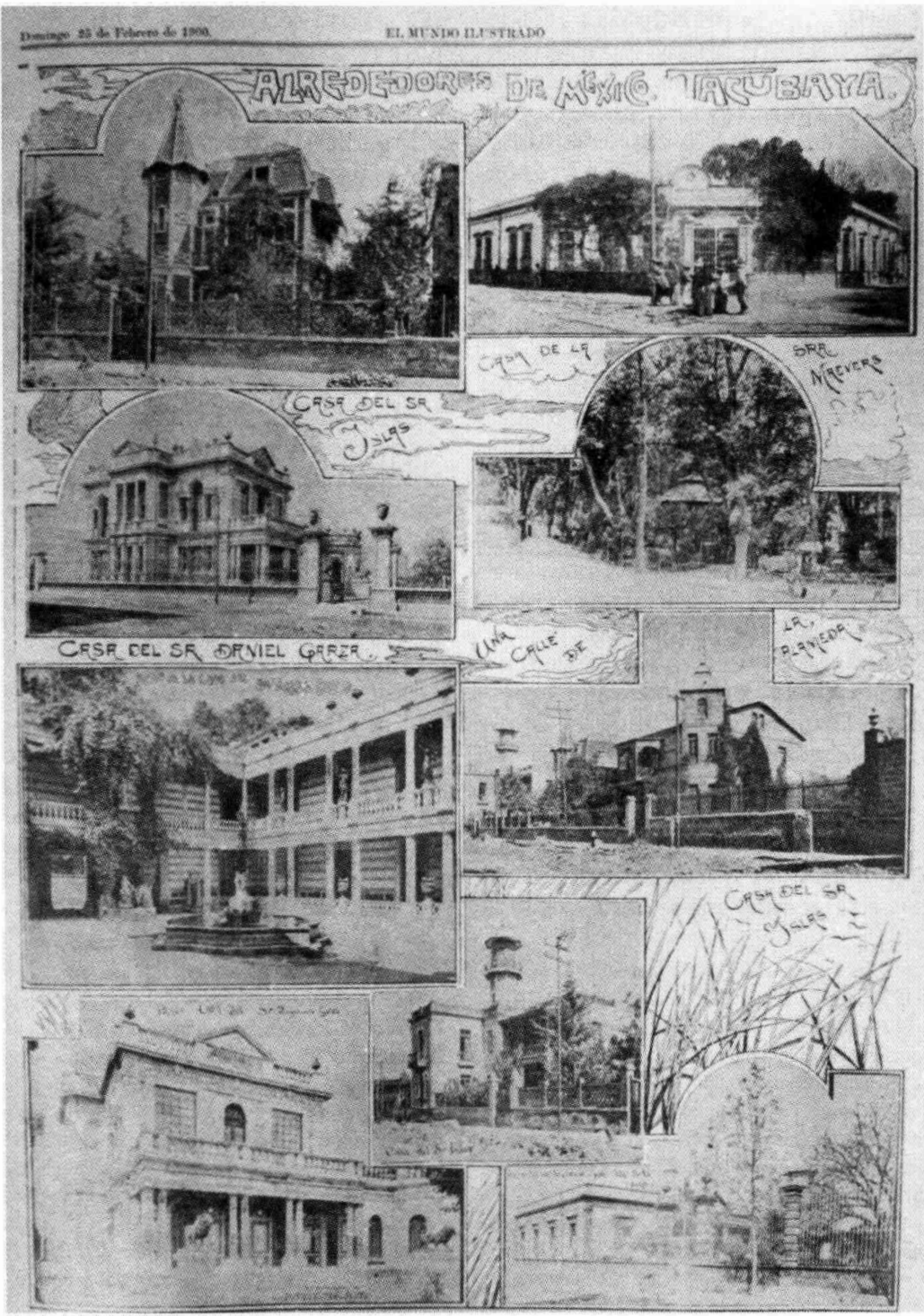


cha parcialmente por los propietarios españoles de solares donde, a cambio de una renta, se les permitió instalar sus jacales, además de la constitución de familias de distinta composición étnica. ${ }^{34}$ Paralelo al asentamiento indígena en la traza capitalina se produjo el crecimiento demográfico de la población no india, vía un lento crecimiento natural y una continua inmigración, que acabó ocupando espacios en los diversos barrios indios.

El padrón de 1777, al aportarnos una división étnica por parroquias, nos permite observar estos fenómenos, tal y como podemos ver en el cuadro 4.

El desglose por etnias y parroquias muestra los restos del principio de zonificación, de forma tal que cuatro partoquias que ocupaban la traza de la ciudad española, con su territorio de expansión hacia San Cosme y sus inmediatos alrededores (básicamente el Sagrario y San Miguel), representaban $73.1 \%$ de la población española y $62.2 \%$ de la población de castas (mestizos, castizos, mulatos, negros, etc.), toda vez que la población indígena apenas alcanzaba $37 \%$ del total de su población. Por el contrario, el restante $63 \%$ de la población indígena se localizaba en las otras diez parroquias, es decir en la periferia de la urbe que coincidía grosso modo con sus parcialidades indias. Por otra parte, frente a las continuas protestas de autoridades civiles y eclesiásticas de la ciudad a lo largo de los siglos XVII y XVIII, ${ }^{35}$ el mismo padrón evidencia la ocu-

34 O'Gorman, "Reflexiones", 1938, pp. 809-811.

35 Tenemos un claro ejemplo de esta actitud en los informes que fueron recopilados con ocasión del motín de la ciudad de México de 1692, unidos bajo el ilustrativo título de Autos sobre los inconvenientes de vivir los indios en el centro de la ciudad, reducción a sus ba- pación del territorio de las parcialidades de indios por la población española y de castas. Así, las diez parroquias restantes de la ciudad, constituidas en 1772 sobre el territorio de los barrios indios, no tenían una composición demográfica mayoritariamente indígena. De hecho, los 18384 habitantes empadronados como indios apenas representaban $44.2 \%$ de su población, mientras el restante $55.8 \%$ lo formaban españoles y castas. El padrón de 1777 sacaba a la luz la expansión que la población española y de castas babía tenido sobre el territorio de las dos parcialidades de indios de la ciudad de México a lo largo de los siglos XVII y XVIII. Únicamente los territorios de los curatos de Santa Cruz Acatlán y Santo Tomás, al sureste de la ciudad, de San Antonio de las Huertas, al oeste y de Santa Ana al noroeste, todos ellos periféricos y con escasa importancia demográfica, se mantuvieron de facto como espacios predominantemente indígenas.

\section{ESTRUCTURA FAMILIAR, HOGARES E INMIGRACIÓN}

Con el nivel de agregación de datos que presenta el padrón del arzobispado de México de 1777 , dada su estructuración en cuadros-resumen elaborados a partir de las listas de población de cada curato, no es posible profundizar mucho en estos aspectos aunque sí se pueden aportar

\footnotetext{
rrios y doctrinas y los térninos a que deben éstos arreglarse, sin incorporarse con lo principal de la ciudad, para su mejor gobierno, y los informes pedidos sobre esto a los ministros de doctrina. 21 junio 1692, en Archivo General de la Nación (en adelante AGN), Historia, vol. 413, fs. 1-24. Véase O'Gorman, "Inconvenientes", 1938.
} 
Cuadro 4. Distribución étnica de la población en las parroquias de la ciudad de México, 1777

\begin{tabular}{|c|c|c|c|c|c|c|c|}
\hline Parroquia & Españoles & Porcentaje & Castas & Porcentaje & Indios & Porcentaje & Total \\
\hline Sagrario & 20501 & 40.8 & 7573 & 29.7 & 4594 & 15.7 & 32668 \\
\hline Santa Caterina & 6138 & 12.2 & 3797 & 14.9 & 3461 & 11.8 & 13396 \\
\hline Santa Veracruz & 4741 & 9.4 & 2762 & 10.8 & 1661 & 5.7 & 9164 \\
\hline San Miguel & 5352 & 10.7 & 1733 & 6.8 & 1210 & 4.1 & 8295 \\
\hline Santa Cruz y Soledad & 2627 & 5.2 & 1441 & 5.6 & 2673 & 9.1 & 6741 \\
\hline San Pablo & 2625 & 5.2 & 1497 & 5.9 & 2524 & 8.6 & 6646 \\
\hline Santa Ana & 1107 & 2.2 & 381 & 1.5 & 4052 & 13.8 & 5540 \\
\hline San Sebastián & 2195 & 4.4 & 2051 & 8.0 & 1194 & 4.1 & 5440 \\
\hline San José & 1992 & 4.0 & 1557 & 6.1 & 1791 & 6.1 & 5340 \\
\hline Salto del Agua & 937 & 1.9 & 1187 & 4.7 & 1126 & 3.8 & 3250 \\
\hline Santo Tomás & 381 & 0.8 & 473 & 1.9 & 1852 & 6.3 & 2706 \\
\hline Sta. María la Redonda ${ }^{a}$ & 905 & 1.8 & 505 & 2.0 & 620 & 2.1 & 2030 \\
\hline Santa Cruz Acatlán & 198 & 0.4 & 393 & 1.5 & 1345 & 4.6 & 1936 \\
\hline San Antonio Huertas & 507 & 1.0 & 173 & 0.7 & 1207 & 4.1 & 1887 \\
\hline Total $^{b}$ & 50206 & 100.0 & 25523 & 100.0 & 29310 & 100.0 & 105039 \\
\hline
\end{tabular}

${ }^{a}$ En el caso de Santa María la Redonda se ha procedido a rectificar el cuadro final del padrón del arzobispado que intercambió el total de mestizos por el de indios ( 270 y 620 respectivamente). En el resto de casos, dados los mínimos errores detectados, se dejaron las cifras aparecidas en el padrón.

${ }^{\mathrm{b}} \mathrm{Sin}$ incluir religiosos, colegiales, militares ni sus sirvientes.

Fuente: Sánchez, Padrón, 2003, pp. 142-145.

ciertos elementos si comparamos los datos de la ciudad capital con los de la archidiócesis, así como los datos de las diversas parroquias de la ciudad entre sí.

El primer factor que destaca es el de la relación entre individuos/familia. En la medida en que no poseemos la mayoría de los padrones preparatorios no podemos determinar con claridad la unidad censal que sirvió de base para su elaboración, ya fuese el hogar o las familias, a pesar de que el padrón indica en todos los curatos el número de familias. ${ }^{36}$

Asumiendo las propias divisiones del padrón por familias, sobresalen ciertos re-

${ }^{36}$ Sánchez, Padrón, 2003 , p. 48. sultados. Así, mientras la proporción de individuos por familia en el arzobispado es de 4.2, dato muy próximo a lo planteado por Gonzalo Aguirre Beltrán para el total de Nueva España, ${ }^{37}$ en la ciudad de México su proporción se eleva a 4.4 individuos por familia. ${ }^{38}$

Ahora bien, esto no significa necesariamente unas familias con una base de-

${ }^{37}$ Aguirre, Población, 1989, p. 220.

${ }^{38}$ Un dato que si se desglosa por parroquias presenta una gran disparidad, ya que algunas de ellas, caso del Sagrario, San Miguel y Santa Veracruz, tenían una proporción superior $(4.7,4.6$ y 4.5 , respectivamente), mientras que otras como Santo Tomás, Salto del Agua o Santa María la Redonda tenían una proporción de individuos por familia inferior a los 3.3. 
mográfica más amplia producto de una mayor descendencia. Antes al contrario, si esta proporción de individuos por familia la correlacionamos con los datos que surgen de la división por estados civiles determinados en función de dos sacramentos, comunión y matrimonio, podemos aclarar este aspecto. Pero previamente hemos de aclarar el uso dado en la época al concepto "estados".

En la determinación de su significado volvemos a encontrar apoyo en el Diccionario de autoridades, el cual los definía en los siguientes términos:

El ser actual y condicional en que se halla y considera alguna cosa. Vale también, comúnmiente la especie, calidad, grado y orden de cada cosa: y por eso en las repúblicas se distinguen, conocen y hay diversos estados, unos seculares y otros eclesiásticos [...] Estado. Es también el que tiene o profesa cada uno y por el cual es conocido y se distingue de los demás: como de soltero, casado, viudo, eclesiástico, religioso, etcétera. ${ }^{39}$

Se aprecia que, si bien las calidades hacían referencia a lo inmutable de la sangre y el linaje, a lo que constituía el ser de las cosas, los estados apelaban a lo contingente, a lo que podía mutar según las circunstancias.

Aunque, tal y como hemos visto, la proporción individuos/familia es superior en la ciudad que en la archidiócesis, la correlación de este factor con los estados de "párvulos", solteros/solteras y viudos/ viudas, presentes en el padrón de 1777, arroja luz sobre el tipo de familias que existían en la ciudad.

${ }^{39}$ Real, Diccionario, 1990, t. II, p. 623. Sánchez, Padrón, 2003, pp. 40-42.
Por lo que respecta a los párvulos, cabe indicar que generalmente en los padrones que se realizaban en el periodo colonial no se los inscribía, ya que su presencia no era necesaria a los efectos del fin perseguido, ya fuesen las matrículas de tributarios, ya los padrones de milicias o bien determinados libros eclesiásticos relacionados con el cumplimiento de los deberes de los feligreses, en especial comunión, matrimonio y penitencia. A menudo su número se suele inferir a partir de determinados cálculos y estimaciones. Sin embargo, tal y como vimos, una peculiaridad del padrón ordenado por Carlos III en 1776 era la obligatoriedad de incluir a toda la población.

¿Qué se entendía por párvulo en el mencionado padrón? Ni la real orden de $1776 \mathrm{ni}$ las instrucciones elaboradas para su realización especifican con toda claridad a quienes se incluía bajo este rubro. Así, en las instrucciones de Manuel de Flores del 10 de marzo de 1777, la definición de párvulos era: "Por solteros y solteras para la formación de este padrón se entenderán los que tienen ya edad bastante para casarse, y por párvulos los que no llegan a ella." $40 \mathrm{Al}$ no especificarse en ningún momento qué edad se consideraba apta para poder contraer nupcias, el término párvulo no tiene un contenido preciso. ${ }^{41}$

${ }^{40}$ Archivo Histórico del Arzobispado de México (en adelante AHAM), fondo Episcopal, Secretaría Arzobispal, Padrones, caja $9 \mathrm{CJ} /$ libro 6 . Las cursivas son mías.

${ }^{41}$ En la medida en que la categoría que seguía a párvulos era la de solteros, su límite queda bastante impreciso, ya que, tal y como indica Cecilia Rabell, bajo esta última categotía podían quedar personas no casadas de siete, once e incluso catorce años. Véase Rabell, "Descenso", 1993, p. 28. 
Varios elementos nos permiten precisar en qué rango se movieron los diversos autores del padrón del arzobispado de México de 1777. En tres casos de padrones particulares de curatos que luego se incorporarían al resumen general, concretamente, el de Santiago de Querétaro, el de Pilcaya y el de Cempoala, se asienta que por párvulos se estaban refiriendo a los hombres que no llegaban a los catorce años y por párvulas a las que no alcanzaban los doce. ${ }^{42}$ Además, y únicamente como orden de magnitud, si sacamos el porcentaje de población empadronada en 1777 como párvulos (a sabiendas de que esta condición se alargaba en el caso de los hombres, lo cual introduce distorsiones) respecto de la población total y lo comparamos con la división por edades de la población de la intendencia de México en 1791, podemos ver que lo indicado en los tres padrones particulares citados con anterioridad se aproxima bastante a la realidad. Así, en 1777, el porcentaje de párvulos respecto del total de la población del arzobispado de México era de $35 \%$, mientras que en el padrón de Revillagigedo, la suma de grupos de edad de cero a nueve años de la intendencia de México daba un porcentaje de $30 \%$, y si se añadía la población de entre diez y catorce años ascendía a $40.3 \% .{ }^{43} \mathrm{Si}$ conside-

${ }^{42}$ Concretamente el padrón del curato de Cempoala decía: "Padrón de las personas y familias que tiene el curato de Cempoala de todas las castas, advirtiendo que los hombres que no llegan a los catorce años y las mujeres que no llegan a los doce van notados por párvulos y párvulas." Véase AGN, Bienes nacionales, leg. 403, exp. 6. Para Pilcaya véase AGN, Bienes nacionales, leg. 628, exp. 31; y para Santiago de Querétaro, AHAM, fondo Episcopal, Secretaría Arzobispal, Padrones, caja $9 \mathrm{cL} /$ libro 6.

${ }^{43}$ Castro, México, 1988, p. 185. ramos lo planteado en los padrones de Cempoala, Santiago de Querétaro y Pilcaya, esto es, una poblaciôn masculina hasta los trece años y una femenina hasta los once años, el porcentaje de $35 \%$ respecto del total, que es el que resulta en el padrón del arzobispado de México de 1777, parece bastante verosímil. ${ }^{44}$ Por lo que hace al estado de solteros/solteras y viudos/viudas su definición, evidentemente, no tenía relación con temas de edad sino con la situación de los sujetos respecto del sacramento del matrimonio.

Pues bien, aunque en 1777 el tamaño de "las familias" (tal y como aparece asentado en el padrón arzobispal) era más grande en la capital virreinal que en el resto de la archidiócesis, el porcentaje de párvulos de la ciudad (concretamente $25.3 \%$ con respecto a $34.9 \%$ del arzobispado), así como la cantidad de población en edad de contraer nupcias y que no lo había hecho, es decir, solteros y solteras ( $27 \%$ de la población citadina respecto a $16.9 \%$ de la archidiócesis), unido al porcentaje de viudos/viudas de la urbe (11.5\%) en relación con el territorio arzobispal (6.9\%), nos habla de unidades familiares/hogares capitalinos más extensos, no como consecuencia de un mayor crecimiento natural -la proporción de párvulos de la ciudad era inferior a la del arzobispado- sino como resultado de la conformación de unidades familiares/hogares que englobaban individuos que no habían contraído nupcias o que eran viu-

44 Esto no obsta para que en determinados padrones hayamos podido constatar que el límite de los párvulos se hubiese establecido en la franja de los diez u once años. Véase Padrón de Ixtapaluca y padrón de Malacatepec, en AGN, Bienes nacionales, leg. 403, exp. 7 y leg. 388 , exp. 3. 
dos, los cuales no necesariamente estaban unidos por lazos de sangre sino por redes sociales múltiples. En unos casos se encontrarían conviviendo con una familia a causa de su situación de criados, sirvientes, aprendices de talleres o comercios, los cuales eran inscritos en las casas de sus patronos, mientras que en otros casos se trataría de acuerdos entre individuos y familias con miras a sobrellevar mejor las dificultades económicas que implicaban subsistir en la capital virreinal. Es más, ciertos estudios basados en la comparación de varios padrones capitalinos (1753, 1790 y 1811) muestran el aumento de los hogares familiares múltiples, en especial, en la población de clase baja, a medida que empeoraron las condiciones de vida de la población de la capital virreinal en el periodo tardocolonial. ${ }^{45}$ Hay que indicar que esta caracterización se refiere a los datos capitalinos ya que, si tenemos en cuenta el resto de curatos del arzobispado registrados en el padrón de 1777 , observamos hogares con una menor población posiblemente constituidos de forma mayoritaria por relaciones de parentesco, en especial en las zonas rurales del arzobispado.

\footnotetext{
45 Pescador, Bautizados, 1992, p. 191; Scardaville, "Trabajadores", 2002, pp. 218-234. Como ejemplo de la necesidad de estos "arreglos" podemos apreciar que en la parroquia de El Sagrario existían en 1777 más de 1000 familias arrimadas que se incorporaban a los 4977 hogares/viviendas censados en el mencionado curato capitalino, tomando en cuenta únicamente las familias que disponían de su propio hogar y las que compartían vivienda ajena, y haciendo omisión de las familias de sirvientes. Véase Gonzalvo, "Farnilias", 2001, p. 97.
}

\section{Proporción bombres-mujeres en la ciudad} de México

Un indicador que apoya la idea de una estructura familiar/hogar más amplia en la ciudad que en el resto del arzobispado lo encontramos en el análisis de los procesos de inmigración. El óptimo para estudiar la migración del campo a la ciudad de México en una situación preestadística procedería de la combinación de diversas fuentes, actas matrimoniales, padrones parroquiales, censos civiles ( $\nu . g$. intendencias), etc., a partir de las cuales se estableciese, entre otros, el índice de masculinidad (número de hombres por cada 100 mujeres). ${ }^{46}$

Con la fuente que estamos analizando aquí no se puede proceder a realizar un estudio en profundidad de este factor. Varios motivos lo dificultan. Los resúmenes generales, tanto de la ciudad como de cada una de sus catorce parroquias, no establecieron el total de hombres y de mujeres. Si bien la suma de los inscritos como casados (dividiéndolos entre dos), más los viudos/viudas y solteros/solteras que aparecen en columnas separadas, iría en esta dirección; la agregación de los párvulos y párvulas en una única columna lo impide. Aquí no podríamos realizar lo mismo que con el estado "casado", ya que, tal y como indicamos, en el caso de los párvulos este estado no se determinaba de igual manera para los hombres que para las mujeres. Por lo general, vimos que en los primeros era hasta los trece años y en éstas hasta los once años. A partir de esas edades pasaban a la condición de solteros y solteras. Por tanto, la colum-

${ }^{46}$ La proporción de hombres-mujeres [( $\mathrm{bmm} /$ muj) $\times$ 100]. Pescador, Bautizados, 1992, p. 107. 
na de los párvulos presenta una proporción más grande de hombres que de mujeres pero no sabemos exactamente el porcentaje. Por el contrario, la proporción de solteros/solteras presenta un mayor númeto de mujeres que de hombres por esa misma razón.

Sin embargo, esto no constituye un obstáculo insalvable para el análisis del problema de la inmigración ya que el estado más apto para tratarlo es el de la población inscrita como "solteros/solteras", es decir, población a partir de los doce años en el caso de las mujeres y de catorce en el de los hombres, en edad de trabajar y sin lazos matrimoniales, lo cual facilitaba su movilidad laboral, en especial si atendemos a su desigual distribución en el territorio de la ciudad de México. La gráfica 2 ilustra el fenómeno al que aludimos.

Si bien la proporción entre solteros y solteras en el arzobispado de México era muy similar ( 104.7 hombres por cada 100 mujeres), ${ }^{47}$ la desproporción entre solteros y solteras en la ciudad de México es extrema: 64.5 solteros por cada 100 solteras. Un desequilibrio que no puede ser atribuido únicamente a la distinta edad en que eran registrados como tales. Esta falta de proporción entre hombres y mujeres de la capital, así como en otras ciudades de Nueva España (Querétaro, Valladolid) ya había sido indicada por Alejandro de Humboldt en $1803 .{ }^{48}$

${ }^{47}$ Esta anomalía, dada la consideración que hemos realizado de la distinta edad a partir de la cual se planteaba a alguien soltero y soltera (catorce y doce años respectivamente), se basa en un subregistro de la población femenina soltera indígena. Véase Apéndice cuadro 3.

${ }^{48}$ Pescador, Bautizados, 1992, p. 112. Para un trabajo que analiza temas como el índice de masculi-
Lo interesante del padrón de 1777 es que nos permite apreciar esta desproporción en el conjunto de la ciudad sin limitarnos a los análisis realizados por el científico prusiano sobre dos parroquias (El Sagrario y Santa Cruz y Soledad) o por Juan Javier Pescador sobre la parroquia de Santa Caterina. Una desproporción que podemos ver desglosada por parroquias. Así, las cuatro parroquias creadas en 1772 que ocupaban la antigua traza capitalina (El Sagrario, San Miguel, San Pablo y San Sebastián), ${ }^{49}$ presentan una desproporción similar o todavía más extrema que la del total de la capital: San Sebastián, 49.9 solteros por cada 100 solteras; San Pablo, 55.5; El Sagrario, 58.3 y San Miguel, 65.2. El resto de parroquias, constituidas sobre el territorio externo a la traza, jurídicamente en los barrios de indios, muestran una proporción de solteros frente a solteras claramente superior al del total capitalino que, recordamos, era de 64.5 solteros por cada 100 solteras. Al respecto, destaca que tres parroquias de composición mayoritariamente indígena, San Antonio de las Huertas, Santa Cruz Acatlán y Santo Tomás la Palma, presentara un fuerte equilibrio entre solteros y solteras, o incluso una proporción superior de aquéllos.

nidad o las proporciones de celibato en la principal parroquia de la ciudad, El Sagrario, véase Gonzalbo, "Convivencia", 2001.

${ }^{49}$ En el caso de San Pablo esto fue así dado que en la división parroquial de 1772 pasó a ocupar diez cuadras de la antigua parroquia de españoles de San Miguel, situadas al sureste de la traza capitalina, mientras que San Sebastián ocupó el extremo noreste de la traza, en unas cuadras que anteriormente pertenecieron a la parroquia de españoles de Santa Caterina Mártir. Moreno, "Territorios", 1981, p. 189, e "Historia", 1985, p. 568. 
Gráfica 2. Proporción de solteros respecto a la de solteras en las parroquias de la ciudad de México, 1777

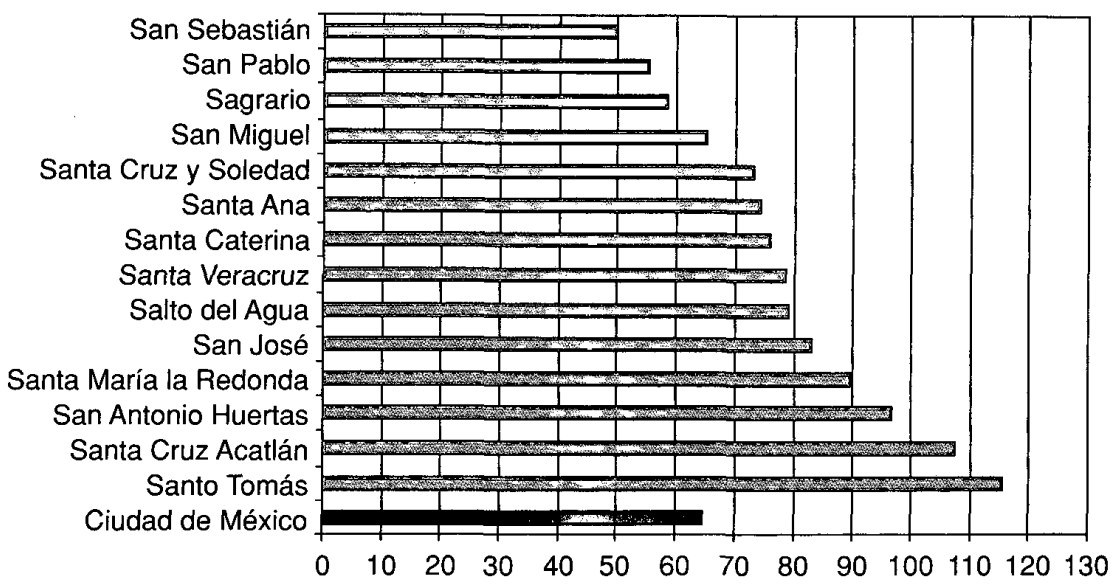

Fuente: Sánchez, Padrón, 2003.

La explicación a estos desequilibrios cabe buscarla en la existencia de un fenómeno inmigratorio básicamente femenino, mujeres jóvenes a partir de los doce años, mayoritariamente criollas y de castas, ${ }^{50}$ que se dirigieron preferentemente a la zona central de la ciudad, lugar en el cual podían encontrar más fácilmente empleo, especialmente en el sector servicios. $^{51}$ De forma paralela, el análisis de Juan Javier Pescador sobre Santa Caterina Mártir muestra cómo en una parroquia constituida tras la reforma de 1772 de una

\footnotetext{
${ }^{50}$ Ver la proporción por etnias de solteros/solteras de las parroquias de El Sagrario, San Miguel, San Pablo y San Sebastián. Véase Sánchez, Padrón, 2003, pp. 142-145.

51 Pérez y Klein, "Población”, 2002, pp. 70-71.
}

forma dual, esto es, una zona plenamente urbanizada con predominio de población española y de castas al sur del curato que lindaba con la antigua traza española y una zona semirrural al norte del mismo de mayoría indígena, la mayor desproporción entre hombres y mujeres jóvenes se daba en el área próxima a la traza, dadas las mayores oportunidades de empleo, en este caso concreto la real fábrica de cigarros y las casas de familias pudientes. ${ }^{\zeta_{2}}$

De forma paralela esta sobrerrepresentación de población femenina joven en

52 "Lo cual haría evidente que el proceso migratorio de mujeres jóvenes no afecta la zona periférica de los indígenas y se orientaba sobre todo a los atractivos que ofrece -sobre todo en empleo- el centro de la parroquia". Pescador, Bautizados, 1992, p. 122. 
edad de casarse en estas cuatro parroquias acabó provocando una saturación en el mercado nupcial de dichas parroquias. Es sintomático al respecto que, en correspondencia con el mayor número de mujeres solteras que de solteros, esas mismas parroquias (San Sebastián, El Sagrario, San Miguel y San Pablo) presenten la menor proporción de viudos respecto al número de viudas (véase gráfica 3). ${ }^{53}$

Frente a un lógico desequilibrio de género en el número de viudos en relación con el de viudas, en el caso de la ciudad de México del orden de 33.5 viudos por cada 100 viudas, esta desproporción se vuelve extrema en el caso de las cuatro parroquias citadas con anterioridad, al mostrar una proporción de entre 15.1 —en el caso de San Sebastián- hasta 19.4 -en el de la parroquia de San Pablo. El mayor número de población femenina soltera en esas parroquias que en el resto de la ciudad, producto de la inmigración, permitió reducir al mínimo el número de viudos, los cuales ante la defunción de su cónyuge podían contraer más fácilmente segundas nupcias. De forma inversa sucedía con las parroquias mayoritariamente indias de la ciudad (Santa Ana, Santo Tomás la Palma, Santa Cruz Acatlán y San Antonio de la Huertas), en las cuales el mayor equilibrio entre solteros y solteras dificultaba a los viudos de esas parroquias volverse a casar. De ahí que la proporción de viudos respecto a viudas de estos curatos fuese claramente superior al del total de la urbe capitalina.

53 Dado el estado de conservación del original del Padrón de 1777 conservado en Sevilla, no ha sido posible determinar los totales de viudos y viudas de la parroquia de la Santa Veracruz.

\section{CONCLUSIONES}

El análisis en diversos niveles del padrón de 1777 , así como su comparación con otros padrones y estimaciones demográficas del siglo XVIII y la primera mitad del siglo XIX, nos muestra que la ciudad de México tuvo un lento crecimiento demográfico a lo largo del periodo $1746-$ 1852 , del orden de $0.67 \%$ anual, aunque desigualmente distribuido ya que el incremento fue mucho más lento a lo largo de la segunda mitad del siglo XVIII $(0.48 \%$ anual) que en la primera mitad de la siguiente centuria $(0.92 \%)$. Un ritmo pausado que se corresponde a las reiteradas e intensas crisis demográficas vividas por la capital a finales del periodo tardocolonial. En este marco, la información de 1777, que arroja una población en la ciudad de 112462 habitantes, mostraría el final de un ciclo de evolución demográfica positivo que arrancaría desde la epidemia de matlazahuatl de 1737.

Este contingente de población capitalina que hacía de ella la ciudad más poblada de todo el continente, tenía un reflejo en su distribución en el territorio al presentar una densidad demográfica muy elevada, 9713 habitantes por kilómetro cuadrado, en un área urbana y semirrural que ocupaba alrededor de $10.62 \mathrm{~km}^{2}$. Pero esta densidad de población, como otros componentes de la urbe, no refleja los grandes contrastes que la conformaban. Así, en el pequeño territorio de $1.83 \mathrm{~km}^{2}$ que conformaban las parroquias de El Sagrario y San Miguel, es decir, $17.2 \%$ del área de la ciudad, se concentraba más de $39 \%$ de su población, con densidades que superaban los 20000 hab/kilómetro cuadrado. Por el contrario, las áreas periféricas, semirrurales y jurídicamente ads- 
Gráfica 3. Proporción de viudos respecto a la de viudas en las parroquias de la ciudad de México, 1777

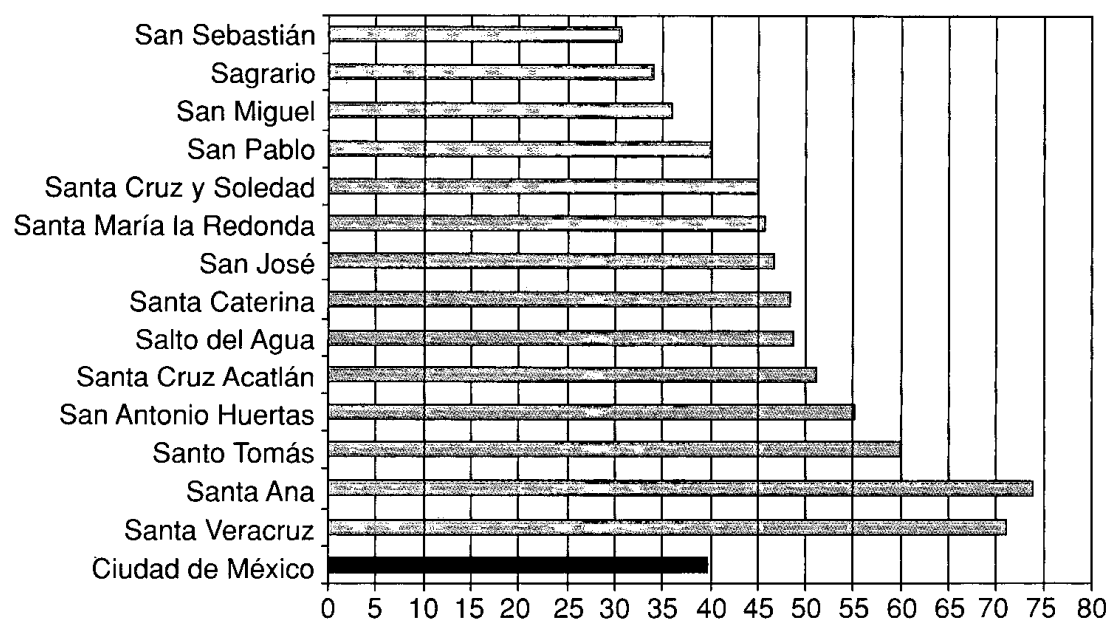

Fuente: Sánchez, Padrón, 2003.

critas a las dos parcialidades de indios de la ciudad (San Juan Tenochtitlan y Santiago Tlatelolco), presentaban densidades que no superaban los $10000 \mathrm{hab} / \mathrm{km}^{2}$.

Asimismo, la ciudad capital poseía una composición étnica disímil al resto del arzobispado de México, el cual constituía el territorio más poblado y diverso del conjunto virreinal, con una mayoría de población inscrita con calidad de españoles, alrededor de $50 \%$ del total, mientras la población indígena apenas alcanzaba $27 \%$, toda vez que en el resto del territorio de la archidiócesis los porcentajes se invertían, 14 y $67 \%$ respectivamente. Unos volúmenes de población y una composición étnica que muestran la primacía política y económica desempeñada por la ciudad de México en el conjunto de Nueva España como sede de los poderes virreinales y como mercado articulador de su economía.

De forma similar a lo sucedido con la distribución de la población en el territorio, la distribución étnica de la capital era un indicador de los procesos vividos en la ciudad. Por una parte, dejaba traslucir los restos del viejo proyecto fundacional que pretendió la separación étnica de la población entre indios y gente de razón. Así, en 1777, 73\% de los españoles y $62 \%$ de la población de castas (mestizos, mulatos, castizos, etc.) de la ciudad tenía su residencia en la traza urbana (inicialmente una superficie de trece leguas cuadradas) en la parte central de la antigua 
capital tenochca, ejecutada en 1521. Un área que fue reservada para la población española, toda vez que se obligó al traslado de la población indígena al espacio denominado por los conquistadores "barrios" o parcialidades de indios. En este mismo espacio apenas estaba asentada $37 \%$ de toda la población indígena de la ciudad, la cual vivía mayoritariamente en las parcialidades de indios de México. Por otra parte, los mismos datos del padrón de 1777 nos muestran el quebrantamiento de este proyecto de zonificación étnica en la medida en que registran la ocupación del territorio de dichas parcialidades por parte de la gente de razón, al representar ésta cerca de $56 \%$ de su población (españoles y castas), lo cual significaba que la población indígena había pasado a ser minoritaria en unos espacios jurídicamente establecidos como parcialidades/ barrios de indios.

Internamente, a pesar de los problemas que presenta la fuente, los datos de 1777 indican que la ciudad de México estaba compuesta por unidades familiares/hogares más grandes que el resto de la archidiócesis, 4.2 y 4.4 individuos por familia respectivamente, lo cual no era producto de un mayor crecimiento natural de la población - tal y como se podría suponer-, en la medida en que la población infantil de la urbe, es decir, la base de su pirámide demográfica, era inferior a la del arzobispado. Este tamaño superior de las familias/hogares cabe atribuirla a procesos inmigratorios, en especial de mu- jeres en edad de trabajar, de calidad criolla o de castas (mestizas, mulatas, negras), las cuales acudían a la ciudad con la expectativa de encontrar un empleo en comercios, ciertas manufacturas (caso de la real fábrica de cigarros) y al servicio de familias pudientes. $\mathrm{Al}$ respecto, la desigual presencia de solteras en las distintas parroquias de la ciudad, en especial su mayor proporción en las parroquias del centro (San Miguel, Sagrario, San Sebastián, etc.), es una muestra clara de este proceso inmigratorio. Un movimiento poblacional que tendría consecuencias. Tal sería el caso de sus efectos sobre el mercado nupcial de la ciudad, en la medida en que en esas mismas parroquias centrales se produjo una sobrerrepresentación de mujeres solteras que permitió que los viudos residentes en ellas pudiesen contraer segundas nupcias mucho más fácilmente que los empadronados en otros espacios de la capital.

En síntesis, era una ciudad que crecía lentamente, con crecientes problemas demográficos, desigual en la ocupación del espacio y en su composición étnica, con una relativa escasa población infantil, la cual mantenía su impulso demográfico gracias a procesos inmigratorios, en especial de mujeres jóvenes que acudían a la urbe dadas las oportunidades laborales que allí se ofrecían. Ciudad que, todavía en 1777 , dejaba rastrear en su estructura poblacional el viejo proyecto fundacional étnicamente zonificador, así como su fracaso. 


\section{APÉNDICE}

Cuadro 1. Población de la ciudad de México (1689-1852)

$\begin{array}{lr}\text { Año } & \text { Población } \\ 1689 & 57000 \\ 1746 & 98000 \\ 1753 & 80000 \\ 1777 & 112462 \\ 1790 & 112926 \\ 1792 & 130602 \\ 1804 & 137000 \\ 1805 & 128218 \\ 1811 & 168846 \\ 1813 & 123907 \\ 1824 & 160000 \\ 1833 & 170000 \\ 1838 & 205430 \\ 1846 & 200000 \\ 1852 & 200000\end{array}$

Fuentes: Para 1689, Rubio, "Gente", 1966; 1746, Villaseñor, Theatro, 1992; 1753, Báez, "Planos", 1966; 1777, Sánchez, Padrón, 2003; 1790-1852, Orozco, "Ciudad", 1854, y Davis, "Tendencias", 1972.

Cuadro 2. Población de la ciudad de México en 1777 por clases, estados y calidades

\begin{tabular}{|c|c|c|c|c|c|c|c|c|c|}
\hline & Clérigos & Familias & Casados & Viudos & Viudas & Pámulos & Solteros & Solteras & Totales \\
\hline Españoles & 5469 & 13223 & 18321 & 977 & 4418 & 12193 & 5703 & 8508 & 50465 \\
\hline Indios & & 6645 & 12189 & 784 & 1893 & 8550 & 3171 & 3745 & 30227 \\
\hline Mestizos & & 2814 & 4805 & 180 & 1077 & 3602 & 1002 & 1953 & 13009 \\
\hline Mulatos & & 1509 & 2409 & 123 & 814 & 1573 & 931 & 1530 & 7467 \\
\hline Castizos & & 982 & 1394 & 67 & 294 & 1542 & 324 & 490 & 4088 \\
\hline Moriscos & & 119 & 189 & 29 & 101 & 268 & 88 & 99 & 710 \\
\hline Mestindios & & 74 & 65 & 36 & 27 & 155 & 47 & 54 & 30 \\
\hline Negros & & 34 & 41 & 29 & 51 & 42 & 49 & 103 & 311 \\
\hline Lobos & & 23 & 23 & 9 & 21 & 153 & 32 & 39 & 266 \\
\hline Albinos & & 4 & 6 & 4 & 3 & 26 & 8 & 6 & \\
\hline Coyotes & & 0 & 0 & 0 & 0 & 12 & 0 & 1 & \\
\hline Chinos & & 0 & 0 & 0 & 0 & 0 & 0 & 0 & \\
\hline
\end{tabular}

$\begin{array}{llllllllll}\text { Totales } & 5469 & 25443 & 39996 & 3270 & 9754 & 28482 & 11914 & 18484 & 112462\end{array}$

Fuente: Sánchez, Padrón, 2003, p. 151. 


\section{SECUENCIA}

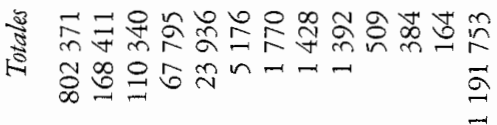

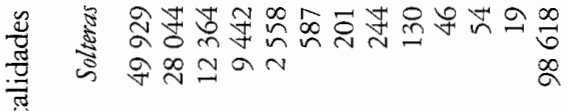

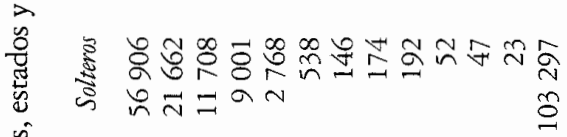

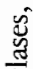

象

즌

$\vec{\forall}$

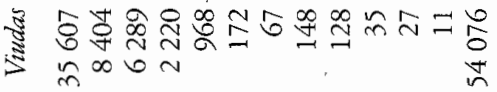

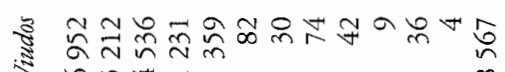

에

i

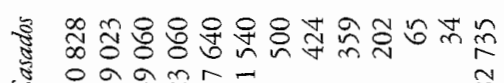

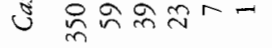

学

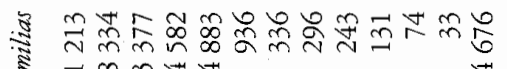

萬

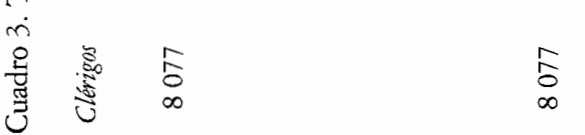

氙

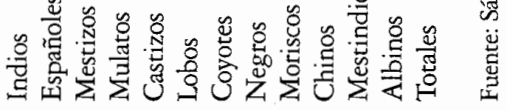




\section{ARCHIVOS}

AGI Archivo General de Indias, Sevilla.

AGN Archivo General de la Nación, México.

AHAM Archivo Histórico del Arzobispado de México, México.

\section{BiBLIOGRAFÍA}

-Aguirre Beltrán, Gonzalo, La población negra en México: estudio etnobistórico, $\mathrm{FCE} /$ Universidad Veracruzana, México, 1989.

-Báez Macías, Eduardo, "Planos y censos de la ciudad de México, 1753", Boletín del Archivo General de la Nación, segunda época, vol. viI, núms. 1-2, enero-marzo de 1966, pp. 407-484.

- "Planos y censos de la ciudad de México, 1753" (segunda parte), Boletín del Arcbivo General de la Nación, segunda época, vol. vIII, núms. 3-4, julio-diciembre de 1967, pp. 485-1155.

- Castro Aranda, Hugo Roberto, México en 1790 (El censo condenado), Foro Nacional de Colegios Profesionistas, México, 1988.

-Dávalos, Marcela, "Los espacios públicos en los barrios indígenas de la ciudad de México. Siglo Xvil" en Carlos Aguirre Anaya, Marcela Dávalos, María Amparo Ros (eds.), Los espacios públicos de la ciudad. Siglos XVIII y XIX, Casa Juan Pablos/Instituto de Cultura de la Ciudad de México, México, 2002, pp. 110-128.

-Davis, Keith A., "Tendencias demográficas urbanas durante el siglo XIX en México", Historia Mexicana, vol. XxI, núm. 3, enero-marzo de 1972, pp. 481-524.

-Gerhard, Peter, México en 1742, José María Porrúa e Hijos, México, 1962.

-Gibson, Charles, Los aztecas bajo el dominio español (1519-1810), Siglo XXI, México, 1984.

-Gonzalvo Aizpuru, Pilar, "Convivencia, segregación y promiscuidad en la capital de la Nueva España" en Clara García y Manuel Ra- mos Medina (coords.), Actas del 3er. Congreso Internacional Mediadores Culturales. Ciudades Mestizas: Intercambios y Continuidades en la Expansión Occidental. Siglos XVI a XIX, CONDUMEX/INAli, México, 2001, pp. 123-138.

- _Familias y viviendas en la capital del virreinato" en Rosalía Loreto (coord.), Casas, viviendas y bogares en la bistoria de México, ColMEX, México, 2001, pp. 75-108.

-Grice-Hutchinson, Marjorie, El pensamiento económico en España (1177-1740), Crítica, Barcelona, 1982.

-Lira, Andrés, Comunidades indígenas frente a la ciudad de México. Tenochtitlan y Tlatelolco, sus pueblos y barrios, 1812-1919, ColmEx, México, 1995.

-Lombardo de Ruiz, Sonia, Atlas bistórico de la ciudad de México, Smurfit/INAH, México, 1996, 2 vols.

-McCaa, Robert, "Calidad, Clase and Marriage in Colonial México: The Case of Parrall, 1788-90", Hispanic American Historical Review, Duke University Press, vol. 64, núm. 3, 1984, pp. 477-501.

-Miño Grijalva, Manuel, "La población de la ciudad de México en 1790 . Variables económicas y demográficas de una controversia" en Manuel Miño Grijalva, La población de la ciudad de México en 1790. Estructura social, alimentación $y$ vivienda, INEGI/COLMEX, México, 2002, pp. 1-52.

-Moreno de los Arcos, Roberto, "Los territorios parroquiales de la ciudad arzobispal", Gaceta Oficial del Arzobispado de México, México, pp. 151-1.73 (reimpreso en Cuadernos de Arquitectura Virreinal, Facultad de Arquitectura, División de Estudios de Posgrado-UNAM, núm. 12, 1981, México.

"En torno a la historia de las divisiones parroquiales de ciudades con planta indígena prehispánica" en Antonio Bonet Correa (coord.), Urbanismo e bistoria urbana en el mundo bispánico, Universidad Complutense de Madrid, Madrid, 1985, t. I, pp. 561-572. 
-O'Gorman, Edmundo, "Sobre los inconvenientes de vivir los indios en el centro de la ciudad", Boletin del Archivo General de la Nación, vol. 9, núm. 1, enero-marzo de 1938, pp. 1-34. ,"Reflexiones sobre la distribución urbana colonial de la ciudad de México", Boletín del Archivo General de la Nación, vol. 9, núm. 4, octubre-diciembre de 1938, pp. 787-815.

-Orozco y Berra, Manuel, "La ciudad de México" en Diccionario universal de bistoria y de geografía, Imprenta de F. Escalante, México, 1854, t. v, pp. 601-783.

-Perdices de Blas, Luis y John Reeder, El mercantilismo: política económica y Estado nacional, Síntesis, Madrid, 1998.

-Pérez Toledo, Sonia y Herbert S. Klein, "La población y la estructura social de la ciudad de México a partir del censo de Revillagigedo" en Manuel Miño Grijalva, La población de la ciudad de México en 1790. Estructura social, alimentación y vivienda, INEGI/COLMEX, 2002, pp. 53-96.

-Pescador, Juan Javier, De bautizados a fieles difuntos. Familias y mentalidades en una parroquia urbana, Santa Catarina Mártir, 1568-1820, COLMEX, México, 1992.

-Rabell Romero, Cecilia, "El descenso de la población indígena durante el siglo XV1 y las cuentas del gran capitán" en El poblamiento de México. Una visión bistórico-demográfica, tomo II, El México colonial, Secretaría de GobernaciónCONAPO, México, 1993, pp. 18-35.

-, "Oaxaca en el siglo XviII. Población, familia y economía”, tesis de doctorado, Colmex, México, 2001.

-Real Academia Española, Diccionario de antoridades, edición facsímil, Gredos, Madrid, 1990 (1a. ed., 1732).
-Rubio Mañé, Ignacio, "Gente de España en la ciudad de México. Año de 1689”, Boletín del Arbivo General de la Nación, segunda época, vol. VII, núms. 1-2, enero-marzo de 1966, pp. 5-406.

-Sánchez-Albornoz, Nicolás, La población de América Latina. Desde los tiempos precolombinos al año 2025, Alianza Universidad, Madrid, 1994.

-Sánchez Santiró, Ernest, Padrón del arzobispado de México de 1777, Archivo General de la Nación, México, 2003.

-Scardaville, Michael C., "Trabajadores, grupo doméstico y supervivencia durante el periodo colonial tardío en la ciudad de México o "la familia pequeña no vive mejor'" en Manuel Miño Grijalva, La población de la ciudad de México en 1790. Estructura social, alimentación y vivienda, INEGI/COLMEX, México, 2002, pp. 209-258.

-Sotomayor, Arturo, Expansión de México, FCE, México, 1975.

-Taylor, William B., Ministros de lo sagrado: sacerdotes y feligreces en el México del siglo XVIll, México, El Colegio de Michoacán/Secretaría de Gobernación, 1996.

-Torre Villalpando, Guadalupe de la, "La demarcación de cuarteles. Establecimiento de una nueva jurisdicción en la ciudad de México del siglo XVII" en Sonia Lombardo Ruiz (coord.), El impacto de las reformas borbónicas en la estructura de las ciudades. Un enfoque comparativo, Gobierno de la Ciudad de México, México, 2000, pp. 89-108.

-Villaseñor y Sánchez, Joseph Antonio, Theatro americano. Descripción general de los reynos $y$ provincias de la Nueva España y sus jurisdicciones, Trillas, México, 1992. 